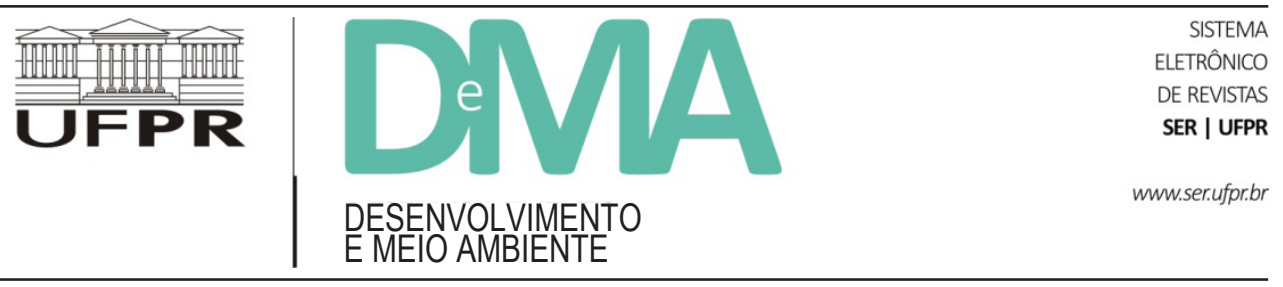

\title{
Sociedade civil e meio ambiente: a atuação das ONGs socioambientais na região metropolitana de João Pessoa - PB e sua contribuição à legitimação social dos problemas ambientais
}

\section{Civil Society and Environment: Socio-environmental NGOs Performance in the Metropolitan Area of João Pessoa - PB and Their Contribution to Social Legitimacy of Environmental Problems}

\author{
Gustavo Ferreira da Costa LIMA ${ }^{1 *}$ \\ ${ }^{1}$ Departamento de Ciências Sociais, Universidade Federal da Paraíba (UFPB), João Pessoa, PB, Brasil. \\ *E-mail de contato: gust3lima@uol.com.br
}

Artigo recebido em 26 de janeiro de 2016, versão final aceita em 3 de agosto de 2016.

RESUMO: O presente artigo é produto de pesquisa realizada na região metropolitana de João Pessoa com o objetivo de investigar a atuação das Organizações Não Governamentais - ONGs - socioambientais nas últimas décadas e como elas têm contribuído para a legitimação social dos problemas ambientais. Teoricamente, explorou a literatura da área, dialogou com as contribuições da Ecologia Política e com os autores que tematizam o ressurgimento da Sociedade Civil nas últimas décadas do século XX. A pesquisa optou por um desenho metodológico qualitativo, explorando a experiência de oito ONGs socioambientais da região por meio de nove entrevistas semiestruturadas com membros representativos dessas organizações. As entrevistas versaram sobre o histórico de formação das entidades, o perfil e as atividades que realizam, as relações que estabelecem com outras esferas sociais, suas estratégias de organização e financiamento, a percepção que têm sobre os problemas ambientais locais, as dificuldades que encontram para sobreviver e o que pensam sobre a cultura ambiental local. Os resultados evidenciaram que ainda são poucas e pequenas as entidades deste tipo na região, que sobrevivem com grande dificuldade a partir, sobretudo, do trabalho voluntário e da contribuição dos próprios sócios. Contudo, a despeito dos problemas que experimentam em seu cotidiano, essas organizações têm desenvolvido um papel fundamental na vida pública da região no tocante à: defesa das causas ambientais, preservação da natureza e da qualidade de vida da população, ampliação da esfera pública, difusão educacional e cultural dos temas e problemas ambientais e ao avanço progressivo da cultura política e da participação democrática.

Palavras-chave: organizações não governamentais; socioambiental; sociedade civil; João Pessoa. 
ABSTRACT: The current paper results from a research developed in the metropolitan area of João Pessoa - PB that has the objective of investigating the socio-environmental NGOs performance in the last decades and the ways it has contributed to social legitimacy of environmental problems. Theoretically, the article was based on local literature, on a dialogue with Political Ecology and the authors debating about the resurgence of Civil Society in the last decades of 20th century. The research adopted a qualitative methodological design to explore the experience of eight local socio-environmental NGOs through nine semi-structured interviews with representative members of these organizations. The interviews focused on the history of NGOs constitution, the actions taken, the relations established with other social spheres, their organizational and financial strategies, the perception they have on local environmental problems, the difficulties faced in order to survive and what they think about local environmental culture. The results showed that the entities of this kind in the metropolitan area still are few and small and surviving, mostly, from voluntary work and contributions of their own members. However, in spite of the problems they have on a daily basis, these organizations have played a fundamental role in regional public life. They were able to do so through the defense of environmental causes, the protection of nature and the quality of life of local population, the broadening of public sphere, the educational and cultural diffusion of environmental issues and the progressive advance of political culture and democratic participation.

Keywords: non-governmental organization; socio-environmental; civil society; João Pessoa.

\section{Introdução}

O presente artigo é produto de pesquisa realizada $^{1}$ na região metropolitana de João Pessoa com o objetivo de investigar a atuação das Organizações Não Governamentais - ONGs - socioambientais nas últimas décadas e como elas têm contribuído para a legitimação social dos problemas ambientais. Tratou-se, portanto, de explorar duas dimensões interligadas do objeto estudado: a primeira voltada à trajetória constitutiva e ao perfil das ONGs pesquisadas e a seguinte interessada nos efeitos e implicações que sua ação produziu, ao longo do tempo, na sociedade local, em termos de reconhecimento e inserção da questão ambiental na cultura e na política locais. As ciências sociais do meio ambiente têm demonstrado que, apesar da objetividade e da facticidade dos problemas ambientais, eles não são reconhecidos e legitimados inerentemente pelo que são, mas dependem de um complexo processo de construção social que envolve a forma como são definidos, apresentados à sociedade e validados como dignos de atenção na agenda política. Neste processo atuam atores das ciências, das mídias, da política, do setor privado, dos movimentos sociais e das ONGs ambientais que investigamos neste artigo (Martell, 1994; Hannigan, 2006).

Para realizar o objetivo geral, a pesquisa considerou um conjunto de objetivos específicos que incluiu: o processo histórico de emergência dessas organizações; os tipos predominantes de ações realizadas; o ideário político e cultural que inspirou sua constituição; as relações que elas têm estabelecido com outras ONGs, com os governos, as empresas, as mídias e universidades locais; suas estratégias de organização e financiamento; a percepção da cultura e dos problemas ambientais locais; e as principais dificuldades que encontram no desenvolvimento do que consideram ser sua missão institucional.

O problema se justifica por diversas razões imbricadas, entre as quais se colocam a escassa

\footnotetext{
1 A pesquisa foi realizada no biênio 2013-14.
} 
produção sobre as ONGs socioambientais locais, o avanço da degradação ambiental urbana resultante da urbanização desordenada, a retração do papel do Estado no cumprimento de suas funções sociais e ambientais e a crise da democracia representativa que deslegitima crescentemente os processos e os agentes da política tradicional e alimenta os anseios de participação social. Esse conjunto de problemas tem valorizado a esfera pública não estatal, onde as ONGs têm papel estratégico.

A literatura sobre a Sociedade Civil tematizou o movimento de ressurgimento político e teórico dessa esfera social a partir de meados da década de 70, que visava, por um lado, definir uma nova esfera de ação social - relativamente distinta do Estado e da economia - capaz de se opor às ameaças sociais e políticas vividas pelos cidadãos, e, por outro lado, refletir criticamente sobre o conteúdo das mudanças sociais em curso (Cohen \& Arato, 1992; Avritzer, 1993; Costa, 1994; Vieira, 2011). Em seu diagnóstico da modernidade ocidental, Habermas (1981a) observou como a crescente interferência do Estado e do Mercado sobre diversos campos da vida social invadiu espaços de socialização, restringiu liberdades e direitos e limitou a participação social dos indivíduos produzindo, como reação, uma multiplicidade de movimentos e ações de resistência por parte da sociedade organizada.

No caso brasileiro, se multiplicaram no período associações, movimentos sociais e ONGs em defesa de reformas, serviços e equipamentos urbanos, da reforma agrária, da educação popular, de liberdades democráticas contra o autoritarismo vigente, do atendimento a diversas carências sociais, de direitos humanos e expansão da cidadania, de demandas ambientais, feministas e das populações negras (Gohn, 2004; Avritzer, 2009).

No campo particular do ambientalismo no Brasil, as ONGs contribuíram para projetar o te- ma na agenda política nacional, na construção de leis, normas e instituições voltadas à preservação ambiental, na formulação de políticas públicas, em campanhas de conscientização e defesa das causas ambientais e na elaboração do diagnóstico dos problemas prioritários nessa área (Herculano, 2000).

A perspectiva teórica do artigo dialoga, por um lado, com a produção recente deste campo de conhecimento e, por outro lado, com referências extraídas da Ecologia Política e da literatura que tematiza o ressurgimento teórico e político da Sociedade Civil no final do século XX, onde se expressam os movimentos sociais e organizações não governamentais - ONGs - em geral e, em particular, os de caráter ambiental.

Esse conjunto de referências fornece um quadro geral que permite captar os novos conflitos decorrentes da expansão global do capitalismo, a crise do Estado - de bem-estar social no norte e desenvolvimentista no sul - e da democracia representativa, o avanço do neoliberalismo, a desagregação da União Soviética (que impactou os projetos de transformação revolucionários) e as mudanças na cultura e nos modos de fazer política, com aportes da contracultura. Nesse ambiente de final do século XX, de crises múltiplas e de incertezas, em diferentes contextos nacionais, movimentos sociais e ONGs emergiram no cenário político-cultural para expressar demandas, conflitos e identidades diferentes dos movimentos operários clássicos que tiveram evidência nas eras industrial e fordista (Roszac, 1972; Offe, 1985; Cohen \& Arato, 1992; Avritzer, 1993; Costa, 1994; Lipietz, 2002; Montaño, 2010; Vieira, 2011).

$\mathrm{O}$ artigo se organiza em cinco seções, além da introdução. A primeira apresenta o contexto e as linhas gerais do marco teórico que orientou a análise. A seção seguinte expõe os caminhos metodológicos percorridos. A terceira, e mais longa seção do texto, 
traz a análise e a interpretação dos resultados da pesquisa e procura dialogar com os objetivos e os referenciais teóricos definidos. A quarta seção analisa as contribuições das ONGs socioambientais à legitimação social dos problemas ambientais na região e a última seção do texto traz as considerações de síntese do conjunto da investigação.

\section{Sociedade Civil e ONGs no Brasil}

É vasto e heterogêneo o debate teóricoconceitual sobre a Sociedade Civil moderna. Para os fins deste artigo, optou-se pela concepção de Cohen \& Arato (1992) que, a partir de interlocução com a noção de mundo da vida da teoria habermasiana, define-a como a esfera de interação social entre o Estado e a economia composta, sobretudo, pelo universo das relações familiares, pelas associações voluntárias, pelos movimentos sociais e meios de comunicação pública. Trata-se, assim, de um espaço social, relativamente autônomo, onde se desenvolve o associativismo civil, se empreendem ações, discutem e disputam questões orientadas à sociedade política para fins de reconhecimento legal, defesa de direitos e elaboração de políticas públicas.

O termo organização não governamental ONG - surgiu no pós II Guerra, criado pela Organização das Nações Unidas - ONU, para designar organizações internacionais não estabelecidas por acordos governamentais voltadas à execução de projetos de desenvolvimento comunitário e a consultorias a órgãos complementares da própria ONU. A partir desse contexto de cooperação internacional, as ONGs foram se adaptando às realidades nacionais e formando um vasto e diversificado campo de ação social privada, sem fins lucrativos e com finalidades públicas, que se constituiu ao longo do tempo, assumindo ênfases filantrópicas, de assistência e apoio aos movimentos sociais populares, de defesa de identidades, direitos humanos e difusos e de filantropia empresarial (Sobottka, 2002; Teixeira, 2003).

Esse universo de ONGs se expandiu no Brasil com o processo de redemocratização da sociedade na década de 1980, de realização da Constituinte de 1988, de crise e descentralização do próprio Estado e de ascensão do ideário neoliberal marcado por valores de eficiência, de produtividade e pragmatismo. Nesse ambiente, as ONGs tenderam a se autonomizar em relação aos movimentos sociais, a se aproximar da gestão governamental e a experimentar as novas possibilidades abertas pela filantropia empresarial (Gohn, 2013).

Gohn (2004) estabelece uma diferenciação entre as ONGs do período 1970/80, oriundas ou herdeiras dos movimentos sociais populares, promotoras de uma cultura de cidadania e participação, que chama de militantes, das novas ONGs do Terceiro Setor dos anos 1990, engendradas por iniciativas empresariais e movidas por uma racionalidade instrumental, mercadológica e de retração do Estado. Menciona ainda nessa tipologia as ONGs meramente filantrópicas, de tradição mais consolidada e aquelas criadas por personalidades do mundo esportivo ou cultural.

Além dessa diferenciação político-ideológica, é necessário registrar a ampla diversidade de sentidos contidos no termo. São diversos os objetivos, as temáticas e os projetos políticos em que estas entidades se empenham; os atores sociais que as protagonizam; o alcance de sua atuação entre escalas locais e globais; as capacidades de financiamento, de organização e profissionalização; as estratégias de ação e mobilização e as relações que estabelecem com os governos e a sociedade abrangente. Essa diversidade inerente ao campo das ONGs e sua di- 
nâmica através de conjunturas históricas, políticas e culturais complexificam e dificultam uma definição inequívoca do termo. Para fins operacionais, usa-se aqui a definição de Landim, que trata as ONGs como um campo identitário e de disputas plural, caracterizando-as, grosso modo, como:

organizações com razoável grau de independência em sua gestão e funcionamento, criadas voluntariamente, sem pretender caráter representativo e sem ter como móvel o lucro material, dedicadas a atividades ligadas a questões sociais, pretendendo a institucionalização, a qualificação do trabalho e a profissionalização de seus agentes, tendo a fórmula "projeto" como mediação para suas atividades, onde as relações internacionais - incluindo redes políticas e sociais e recursos financeiros - estão particularmente presentes. Organizações nas quais, finalmente, o ideário dos direitos e da cidadania é marca de peso, permeando e politizando atividades variadas (Lan$\operatorname{dim}, 2002$, p. 238).

A expansão das ONGs na vida nacional das últimas décadas, sua inserção em diversos campos de atividades civis e em parcerias com governos e empresas e sua presença frequente nas mídias têm levantado controvérsias sobre sua natureza e seu papel social. Algumas dessas questões se referem à confusão comum entre movimentos sociais e ONGs, à falta de representatividade formal dessas organizações frente ao público a que se dirige, à suspeita de substituição do Estado no cumprimento de funções públicas ou à própria possibilidade de algumas ONGs servirem a interesses contrários à ética e ao bem-estar público (Gonçalves \& Menescal, 1996; Herculano, 2000; Dagnino, 2004; Maia, 2010; Montaño, 2010; Gohn, 2013).

Sobre a confusão frequente que trata movimentos sociais e ONGs como organizações semelhantes ou sucessivas no tempo, Montaño (2010) esclarece que os movimentos sociais são constituí- dos por atores sociais portadores de determinada identidade, interesse e pertencimento de classe e que se mobilizam na luta e na defesa de seus próprios interesses, enquanto as ONGs são formadas por sujeitos voluntários ou remunerados, que se mobilizam na defesa de interesses alheios, ainda que possam ter afinidade com eles.

A questão da falta de representatividade das ONGs se refere ao fato de que as ONGs falam em nome do povo, da sociedade civil ou de um grupo social e escolhem ou condicionam cursos de ação para os mesmos sem que tenham uma delegação formal para tanto (Gonçalves \& Menescal, 1996; Herculano, 2000).

A suspeita de substituição de funções do Estado e de despolitização da vida pública tem se acirrado, a partir dos anos 1980/90, em um cenário de crise fiscal, de redução do Estado e desmonte de políticas sociais, quando o ideário neoliberal levou os governos a investir na privatização do setor público e em estratégias de descentralização e terceirização de atividades governamentais, onde as ONGs aparecem como agentes privilegiados (Dagnino, 2004; Pinto, 2006; Montãno, 2010).

Quanto à presumida idoneidade ético-moral da Sociedade Civil e das ONGs, Maia (2010) adverte que as ONGs não são essencialmente boas ou más e nem sempre atendem a motivações democráticas, altruístas e pacíficas, como se tornou costume acreditar. Elas também podem servir a outros propósitos antidemocráticos, fundamentalistas, excludentes e mesmo praticar ilícitos, como demonstram inúmeros casos no país e no mundo atual.

\section{Metodologia}

A pesquisa optou por uma abordagem qualitativa para compreender a formação e a atuação das ONGs socioambientais da grande João Pessoa, assim 
como sua contribuição para legitimar os problemas ambientais regionais. Partiu, assim, da narrativa dos sujeitos que protagonizaram esses processos interpretando os motivos, os significados e as percepções que esses sujeitos atribuíram à sua ação social de pertencimento, representação e defesa da causa ambiental. Nesse desenho metodológico, a pesquisa empreendeu basicamente três momentos principais.

No primeiro momento, fez-se um levantamento documental para identificar, quantificar e caracterizar as entidades ambientais existentes na região metropolitana de João Pessoa em dados cadastrais e em conversas com informantes significativos direta ou indiretamente envolvidos com o campo ambientalista. Essa etapa documental permitiu mapear as organizações e definir o corpo de possíveis depoentes.

Um segundo momento foi dedicado à revisão bibliográfica da literatura pertinente em livros, periódicos e trabalhos científicos, jornais, revistas, páginas e portais na internet, que permitiu atualizar a produção recente sobre a dinâmica da sociedade civil e das ONGs e a relação que mantêm com as demais esferas sociais. Essa etapa permitiu construir as bases teórico-conceituais de compreensão e interpretação do problema da pesquisa. Deve-se registrar que, embora já exista uma grande diversidade de pesquisas publicadas sobre ONGs ambientais nos níveis nacional e internacional, pouco foi possível encontrar com relação às ONGs de meio ambiente na região metropolitana de João Pessoa.

O terceiro momento da metodologia coube à pesquisa de campo propriamente dita, onde realizaram-se nove entrevistas semiestruturadas com nove representantes de oito organizações não governamentais da região metropolitana de João Pessoa e também foi possível observar diretamente seu ambiente e contextos de trabalho. As entrevistas partiram de um roteiro flexível, embora estrutura- do, de questões decorrentes dos objetivos geral e específicos da pesquisa mencionados acima. Dada a escassez de dados secundários sobre o problema estudado, a pesquisa de campo foi de fundamental importância para conhecer e compreender a trajetória e a dinâmica das entidades pesquisadas no contexto local. Todo o material das entrevistas foi gravado e transcrito e constitui a base de dados da presente análise. Foram entrevistas longas, com duração média de uma hora e meia (1h e $30 \mathrm{~min}$ ) e resultados bastante significativos. Os resultados das entrevistas tenderam a se complementar e/ou se sobrepor entre si, ainda que elementos dissonantes e de surpresa também tenham sido registrados ao longo dos depoimentos.

É preciso esclarecer que a unidade de análise da pesquisa - as ONGs socioambientais - foi intencionalmente definida para incluir não apenas ONGs de perfil exclusivamente ambiental, mas também algumas ONGs de perfil mais amplo e que incluem a questão ambiental como uma de suas preocupações e objetivos. Essa decisão se justificou pelo interesse de conhecer o cruzamento da questão ambiental com outras temáticas associadas, pela constatação do reduzido número de organizações de cunho estritamente ambiental na grande João Pessoa e pela consideração epistemológica de que não existem empiricamente problemas ambientais em sentido estrito, separados do social e da sociedade onde se inserem. Acselrad (1992) está entre os autores que rejeita o reducionismo biologista ao afirmar a inseparabilidade entre sociedade e natureza. Para o autor, os problemas ambientais não são problemas da natureza, mas problemas da sociedade que se manifestam na natureza. Portanto, quando o texto fizer referência às ONGs socioambientais, estará considerando tanto as ONGs prioritariamente voltadas às temáticas ambientais quanto as ONGs que têm o meio ambiente como uma de suas temáticas prio- 
ritárias, ainda que se dediquem, simultaneamente, a temáticas educacionais, culturais, de cidadania e de promoção de emprego e renda. E como o grupo das entidades prioritariamente ambientais guarde alguma diferenciação interna, esse aspecto será ressaltado na seção que se dedica à caracterização do perfil das ONGs e das ações que realizam.

Foram, nesse sentido, entrevistados representantes da Associação Paraibana dos Amigos da Natureza - APAN, fundada em 1978; da Escola Viva Olho do Tempo - EVOT, fundada em 1996; da ONG Guajiru, fundada em 2002; da Associação Cabedelense para a Cidadania - ACICA, fundada em 2007; da Acácia Pingo D’Ouro² , fundada em 2000; da Sociedade Naturista de Tambaba - SONATA, fundada em 1996; da Associação dos Moradores e Amigos de Tabatinga - AMATA, fundada em 1995, e da Organização Comunitária de Educação do Meio Ambiente - OCEMA, fundada em 2008.

$\mathrm{Na}$ etapa de análise dos dados, foi definido um conjunto de sete núcleos temáticos que circunscrevem o problema proposto e nortearam sua compreensão. Esses núcleos temáticos decorreram diretamente dos objetivos específicos da pesquisa e estruturaram o roteiro das entrevistas. Compreendem elementos referentes: a) à história e formação do ambientalismo e das ONGs locais; b) à caracterização do perfil das entidades e das ações realizadas; c) às relações que elas têm estabelecido com outras ONGs, com os governos, as empresas, as mídias e as universidades locais; d) às estratégias de organização e financiamento; e) à percepção dos problemas ambientais locais; f) às principais dificuldades que encontram no desenvolvimento do que consideram ser sua missão institucional; e g) à percepção sobre a formação de uma cultura ambiental local. Além destas sete temáticas e de sua convergência, a pesquisa tomou como objetivo genérico a análise da contribuição das ONGs à questão socioambiental regional e a legitimação dos problemas ambientais nesse contexto.

As questões referentes à constituição e à atuação das ONGs locais foram tematizadas, com maior ou menor profundidade e abrangência, por todos ou quase todos os depoentes entrevistados. Como mencionado anteriormente, os depoimentos giraram em torno desses eixos estruturadores que compõem o corpo dos dados ora analisados. A análise permitiu observar diversos pontos de convergência nas narrativas, onde os depoimentos se reforçam mutuamente, ainda que as ênfases sobre um ou outro aspecto de suas trajetórias sejam destacadas entre os diferentes depoimentos, compondo um painel de complementaridades significativo.

A análise procurou, enfim, articular o conhecimento teórico produzido pela literatura sobre o ambientalismo e as organizações não governamentais de caráter socioambiental à dimensão empírica vivida por essas organizações e seus representantes e demais atores sociais envolvidos nessa ação coletiva.

\section{A atuação e os desafios das ONGs socioambientais da grande João Pessoa}

\subsection{História e formação do ambientalismo e das ONGs locais}

Algumas das narrativas trouxeram elementos históricos significativos para compreender a histó-

\footnotetext{
2 A Acácia Pingo D’Ouro foi fundada no ano de 2000 e desenvolveu atividades até o ano de 2006, se encontrando inativa no presente. Foi incluída na pesquisa pela rica experiência que desenvolveu no período de atividade.
} 
ria, a formação da questão ambiental no contexto local e a constituição de um ambientalismo embrionário, composto por associações civis identificadas com esse ideário. São organizações criadas com a finalidade de defender, discutir e difundir no espaço público valores, práticas e políticas ambientais de preservação do meio ambiente.

Esse contexto histórico de surgimento foi marcado por processos como: a pesca da baleia realizada na praia de Costinha, atual município de Lucena, no período de 1911 a 1985; a implantação e os impactos do Proálcool em termos de desmatamento da Mata Atlântica regional, de uso intensivo de agrotóxicos na cultura canavieira e do lançamento do vinhoto nos rios que, em última instância, poluíam também as praias. A preservação do Altiplano do Cabo Branco e a luta para limitar a expansão dos espigões na orla litorânea também foram processos relevantes que motivaram o debate e a mobilização pública contrários aos impactos ambientais e sociais daí advindos. Desses processos, a luta contra a pesca da baleia, interrompida na Paraíba em 1985 durante o Governo Sarney, talvez tenha sido o de maior apelo simbólico, porque expressava os argumentos do discurso ambiental em formação. Tratava-se de apelos para a conservação de espécies ameaçadas, para o direito à vida e reprodução dos animais, na contramão do pensamento antropocêntrico e da subordinação do ambiente natural às necessidades e desejos humanos (Pelizzoli, 2002; Toledo, 2009; Depoimentos 1 e $2^{3}$ ).

Esses processos constatam que a questão ambiental emerge do reconhecimento social de proble- mas e conflitos prejudiciais ao patrimônio ambiental ou cultural e, por conseguinte, à qualidade de vida dos habitantes locais. As mesmas narrativas sobre esse período de formação destacam a participação decisiva de professores e estudantes universitários na organização de movimentos de denúncia, crítica e mobilização que, junto a outros setores midiáticos, deram visibilidade à nova questão ambiental, até então invisível na vida local. A contribuição da comunidade científica às lutas ecológicas, não apenas aqui, mas em todo o mundo, conferiu legitimidade ao ambientalismo nascente, ajudando a deslocá-lo em direção ao centro da agenda política dominante (Viola, 1987; Leis, 1999; Lima, 2011). Isso porque, em sua fase embrionária, que corresponde às lutas contraculturais das décadas de 1960 e 1970 do século XX, o ambientalismo era prioritariamente identificado com movimentos de juventude 4 e com um ideário romântico periférico na agenda político-cultural da época (Roszac, 1972; Carvalho, 2001).

Outro momento de destaque no contexto local foi a participação das ONGs e movimentos ambientalistas na Constituinte Estadual de 1989, quando a militância ambiental pessoense, associada a outros movimentos da sociedade civil - como entidades profissionais, científicas e educacionais -, conseguiu mobilizar 40 entidades com interesses socioambientais afins, conquistando dispositivos constitucionais relevantes não só na área ambiental, em sentido estrito, como também de saneamento, de gestão urbana, de ciência e tecnologia. Essa configuração de rede de movimentos ${ }^{5}$ foi um processo que também se verificou, em nível nacional, nas

\footnotetext{
${ }^{3}$ Os depoimentos citados resultam das entrevistas realizadas na pesquisa de campo e foram apresentados numericamente para preservar a identidade dos depoentes da pesquisa.

${ }^{4}$ Entre os movimentos contraculturais de juventude destacam-se os beatniks, hippies, feministas, de comunidades rurais, pacifistas e antinucleares, entre outros.

${ }^{5}$ Como veremos mais adiante, essa configuração de redes de movimentos e ONGs, presente e possível nos momento de maior efervescência política e cultural, não se manteve como articulação regular, ainda que eventuais parcerias e cooperações entre ONGs se mantenham.
} 
jornadas preparatórias da Conferência do Rio, em 1992, quando os movimentos sociais e ambientais puderam amadurecer a compreensão de que as questões sociais e ambientais não eram antagônicas, mas decorrentes de um mesmo processo de exploração e dominação do capitalismo sobre a natureza e a sociedade. Esse foi um marco decisivo na história do ambientalismo brasileiro, porque foi capaz de diluir o falso dilema que dividia militantes sociais e ambientais, para constituir uma nova compreensão e aliança do que, a partir de então, tem se denominado de socioambientalismo (Carvalho, 2001; Scherer-Warren, 2008).

\subsection{Caracterização do perfil das entidades e das ações realizadas}

Com relação ao perfil das temáticas eletivas e das ações realizadas pelas entidades pesquisadas, cabe diferenciar o universo estudado entre organizações prioritariamente voltadas às temáticas ambientais e outras que, embora tenham a dimensão ambiental entre seus objetivos, também se ocupam de temas educacionais, culturais, entre os quais de defesa da cultura naturista (SONATA), de cidadania e de promoção de emprego e renda. Considerando esse leque de possibilidades, é possível classificar as ONGs Guajiru, Acácia Pingo D’Ouro, AMATA e OCEMA como entidades prioritariamente ambientais, com um foco predominante em problemas ecológicos; a APAN como uma ONG prioritariamente ambiental, mas com um caráter ambiental multitemático, e a ACICA, a EVOT e a SONATA como entidades que têm a questão ambiental como uma de suas prioridades, embora ela não seja exclusiva e conviva com outras prioridades culturais, sociais e políticas. Nesse sentido, destaco a APAN como a ONG ambiental pioneira na cidade e que ainda segue sendo a mais relevante, reconhecida e atuante na região, operando em diversas áreas, como preservação ambiental e urbana, educação ambiental, mobilização de campanhas públicas de defesa ambiental, fiscalização dos órgãos ambientais, participação em conselhos de meio ambiente e de patrimônio histórico e cultural, combate ao desmatamento, à poluição dos rios, a maus tratos contra animais. Entre seus alvos principais, figuram os processos de degradação causados por agentes e atividades diversas, como a produção industrial, o setor imobiliário, a agricultura empresarial e o turismo.

A ONG Guajiru, ainda que tenha projetos de escola e de inclusão social por meio do surfe, tem sua ação prioritária no Projeto "Tartarugas Urbanas", que visa proteger as áreas de reprodução e alimentação das tartarugas marinhas nas praias de João Pessoa e Cabedelo. Ou seja, essas entidades representam tipos ideais que poderiam ser classificados como multitemáticos, no caso da APAN, e monotemático de caráter ecológico, no caso da Guajiru. As demais ONGs estudadas, de caráter prioritariamente ambiental - Acácia Pingo D'Ouro, AMATA e OCEMA -, desenvolvem ações complementares, similares às da APAN, de cunho educativo, de formação, de denúncia contra a degradação e de representação em colegiados, predominantemente municipais, ainda que não tenham o mesmo alcance e amplitude da APAN.

As demais que se dedicam a outros temas além dos ambientais, como é o caso da EVOT, da SONATA e da ACICA, embora também se dediquem à educação, denúncias e representação em conselhos de gestão, incluem em sua agenda outras temáticas culturais, de alfabetização política e de defesa do naturismo que não são comuns às demais ONGs prioritariamente ambientais.

Registre-se que a participação e o desenvolvimento de projetos por meio de editais públicos só 
foi mencionada pela ONG Acácia Pingo D’Ouro e, sobretudo, pela EVOT, que demonstrou maior experiência nessa área.

Outro aspecto a considerar é a heterogeneidade no universo das ONGs analisadas em relação ao número de associados, participação em conselhos gestores de meio ambiente, abrangência da atuação, longevidade histórica, legitimidade e reconhecimento social.

Em geral, as ONGs socioambientais da grande João Pessoa podem ser classificadas como micro-ONGs pelo número reduzido de seus membros e sócios, raramente acima de cem pessoas, sendo que, dos sócios/membros cadastrados, nunca mais que vinte pessoas participam ativamente. $\mathrm{O}$ baixo orçamento mobilizado é outro critério que permite classificá-las como microentidades. Alguns depoentes expuseram, por exemplo, a carência de instalações e infraestrutura e a necessidade do uso de veículos e equipamentos disponibilizados pelos próprios sócios. E, considerando essas limitações, pode-se dizer que realizam muito com os poucos recursos humanos e financeiros de que dispõem.

Quanto à origem social de seus membros, é possível concluir que a maioria das ONGs socioambientais da cidade tenha surgido por iniciativa de setores de classes médias escolarizadas e com acesso ao ensino superior, ainda que isso não signifique que o ideário ambientalista não tenha se expandido pelas demais classes sociais e atingido outros setores mais carentes da população. Esse padrão de classe corresponde ao verificado na experiência histórica brasileira e mesmo na experiência do ambientalismo internacional, com a particularidade distintiva de que, no caso brasileiro e dos países periféricos em geral, o ambientalismo surgido como um ideário originado nas classes médias, ao longo do tempo, tendeu a se difundir e se inserir nas lutas e práticas de setores populares e de populações tradicionais, como é o caso de cooperativas de catadores, de movimentos de agroecologia, de atingidos por barragens, de indígenas, pescadores artesanais, seringueiros e quilombolas e de populações extrativistas, entre outros. Essa expressão popular converge com o que Martinez-Alier denominou de "Ecologismo dos Pobres", para se referir ao ambientalismo empreendido por populações que retiram sua sobrevivência direta do uso de recursos naturais, em contraste com o ambientalismo das classes médias urbanas que, embora sejam prejudicadas pela degradação e se afinem com a defesa do ambiente, não dependem diretamente dele para sobreviver (Pádua, 1991; Tavolaro, 2001; Martinez-Alier, 2007).

\subsection{Relações estabelecidas com outras esferas sociais}

Em sua trajetória social, as ONGs da cidade estabelecem, com discretas diferenças, relações com os diversos setores da sociedade local, a saber: outras ONGs, governos estadual e municipal, secretarias de governo, empresas, Ministérios Públicos estadual e federal, mídias e universidades, entre outras possíveis. Na pesquisa de campo, procurou-se aferir a abrangência e a qualidade dessas relações, que serão tratadas nesta seção.

Num panorama geral, pode-se dizer que, apesar de algumas variações, a maioria das ONGs relatou esforços na busca de criar parcerias entre si, mas também algumas dificuldades que ainda impedem a construção de uma rede de entidades para troca de experiências e para tratar de problemas comuns. Algumas alegam a própria dificuldade de sobrevivência, a agenda sobrecarregada, o pouco tempo e infraestrutura disponíveis ou ainda a prática, por parte de certas entidades, de 
estabelecer negociações individualizadas com o governo para tratar problemas particulares. Esse padrão de comportamento organizacional difere daquilo que a literatura e a experiência apontam nos contextos mais dinâmicos das maiores cidades, no Brasil e no exterior, onde a construção de redes de entidades já se configura como uma tendência virtuosa de comportamento no universo associativista contemporâneo (Scherer-Warren, 2008). E virtuoso porque multiplica o poder reivindicativo, amplia o acervo de informações e conhecimentos e promove novas sinergias culturais e políticas. As iniciativas de ações em rede na região existem, mas esporadicamente, nas grandes datas e eventos, ainda que, mesmo nessas ocasiões, não sejam capazes de agregar e criar laços duradouros de proximidade e parceria.

Com relação a parcerias e projetos com empresas, apenas duas das ONGs entrevistadas relataram experiências e projetos já realizados, como é o caso da parceria da Acácia Pingo D'Ouro com a Natura Cosméticos e dessa e da EVOT com fundos e fundações como o FIES/Itaú, a Fundação ABrinq e o SEBRAE, que são entidades sem fins lucrativos de interesse público, que nominamos do Terceiro Setor e que são custeadas por contribuições empresariais. Portanto, ainda é muito baixa essa interação entre as ONGs socioambientais e as empresas no contexto local, fato que revela as dificuldades de organização e de profissionalização das entidades pesquisadas. Há, contudo, outras razões éticas a explicar essa baixa ocorrência. A APAN, principal ONG socioambiental da grande João Pessoa, deixou claro em seu depoimento que tem em seu estatuto uma norma que proíbe qualquer forma de patrocínio de empresas vinculadas a processos de degradação ambiental, como, por exemplo, a Petrobrás, que disponibiliza um orçamento considerável em editais públicos de projetos com fins ambientais.
A relação com setores da Universidade Federal da Paraíba - UFPB - e do Instituto Federal da Paraíba - IFPB - foi mencionada por diversas entidades por meio de parcerias em projetos, troca mútua de informações e cooperações diversas. Deve-se ressaltar o fato de que, desde sua fundação, muitas das ONGs locais contaram com o apoio e a participação de quadros das universidades em suas equipes, como aparece neste depoimento:

Quase todos os professores que estão hoje ou estiveram na biologia da UFPB foram fundadores $d a$ APAN: Rita Baltazar, Gilson Melo, Robson Tamar, porque eram estudantes na época. Eles se afastaram da entidade, mas, de certa forma, nunca deixaram de pertencer a ela, mesmo porque, quando precisamos de informação científica e de laudos técnicos eles nos fornecem (Depoimento 1).

Por outro lado, muitos dos atuais representantes das ONGs tiveram formação acadêmica profissional nos cursos universitários, fator que, de algum modo, aproximou a relação entre as ONGs e as universidades. Mencionamos anteriormente que essa relação histórica de cooperação entre as universidades e o conhecimento científico por elas produzido e as ONGs agregou legitimidade e reconhecimento social à ação destas últimas e ao próprio ambientalismo em sentido amplo, contribuindo para deslocar a temática ambiental para o centro da agenda política oficial (Leis, 1999; Tavolaro, 2001).

A relação com os meios de comunicação não foi mencionada em todos os depoimentos, mas, novamente, a APAN revelou ter uma boa relação com todos os meios de comunicação locais, que sempre apoiam, divulgam as denúncias e os informes que desejam veicular, como reciprocamente são alimentados pelas fontes da ONG nos episódios ambientais que se transformam em notícia. A depoente lamentou, contudo, a escassa divulgação 
das outras ONGs existentes na região, o que acaba dando a falsa impressão de que a APAN atua sozinha ou de que a defesa ambiental não é importante para a sociedade local. A Acácia Pingo D’Ouro também revelou ter boas relações com a mídia, assim como sua participação regular no Programa da Rádio Tabajara "Espaço Ecológico".

A relação com os governos estadual, municipal ou federal foi o aspecto mais destacado nos depoimentos, tanto em relação à participação em projetos, programas e políticas governamentais quanto à participação política em conselhos gestores das secretarias da municipalidade ou do governo estadual. A EVOT, seguida pela ONG Acácia Pingo D'Ouro, foram as entidades que mencionaram mais parcerias em projetos e programas, ainda que de curto prazo e de limitado alcance com órgãos governamentais dos três níveis da administração, tais como: FUNJOPE - Fundação Cultural de João Pessoa, SEMAM - Secretaria Municipal de Meio Ambiente, EMLUR - Empresa de Limpeza Urbana da Prefeitura, o IPHAN - Instituto do Patrimônio Histórico e Artístico Nacional (superintendência da PB), a CHESF - Companhia Hidrelétrica do São Francisco, o Fundo Nacional do Meio Ambiente, o Banco do Nordeste do Brasil - BNB, a Fundação Banco do Brasil, o Programa de Erradicação do Trabalho Infantil - PETI - da Secretaria Municipal de Assistência Social, entre outras inserções.

Essas parcerias vão desde eventos pontuais na agenda da cidade à participação em projetos de média duração, seja do interesse do governo, seja por iniciativa criadora das ONGs. Nessas parcerias, as ONGs contribuem com sua experiência sobre o problema em foco e prestam algum serviço social que os governos não fazem ou não têm interesse em fazer. As experiências de projetos declarados pelas poucas ONGs que os realizaram foram: Projeto comunitário de erradicação do trabalho infantil no bairro, Projeto de criação de biblioteca e de estação digital na comunidade do Vale do Gramame, Projeto cultural de educação musical e meio ambiente, Projeto de produção de artesanato e de doces por senhoras da comunidade, Projeto de Agenda 21 local, Projeto de gestão integrada da orla marítima de João Pessoa, Projeto praia limpa, Desocupação de áreas públicas e APPs - Áreas de Preservação Permanente, Projeto de ordenamento territorial da Área de Preservação Ambiental - APA - de Tambaba, Projeto de capacitação de professores e Projeto "Plante Cidadania" de plantio de árvores em espaços vazios da cidade de João Pessoa. Esses projetos foram resultado de parcerias realizadas principalmente com a prefeitura municipal e suas secretarias, mas também com órgãos ambientais estaduais e mesmo federais. Alguns deles nasceram da participação em editais de órgãos da administração pública indireta, como é o caso da CHESF, do BNB e da Fundação Banco do Brasil.

A contrapartida material dos projetos locais mencionados tende a ser baixa do ponto de vista financeiro, além de descontínua ao longo do tempo. No caso das parcerias com a prefeitura, os projetos podem resultar em empréstimos temporários de recursos humanos, em programas educativos de capacitações, em cessão de veículos de transporte, em instalações para eventos, em equipamentos físicos, como foi o caso da antena digital cedida, e, nos casos mais bem-sucedidos, na criação de uma escola, um viveiro de mudas ou um parque urbano reivindicado (Depoimentos 1, 2, 3, 4, 5, 6, 7).

Em todos esses casos, as ONGs ocupam espaços que deveriam ser atribuições dos entes estatais, mas, como o alcance das ações empreendidas é limitado em abrangência, no volume de recursos financeiros, técnicos e humanos e descontínuo ao longo do tempo, é mais realista dizer que elas mais complementam a ação estatal do que, de fato, a 
substituem (Sorj, 2005). É inegável, contudo, que, do ponto de vista simbólico, essas intervenções das ONGs produzem um impacto social que, simultaneamente, valoriza a esfera não governamental enquanto desqualifica a ação governamental.

Com relação à participação social em instâncias colegiadas de gestão pública, é inegável que essas possibilidades se multiplicaram desde a Constituição de 1988, resultando em um conjunto de canais e processos participativos, como são os casos dos conselhos gestores, dos orçamentos participativos, das audiências públicas, dos fóruns, conferências e comitês temáticos de participação pública (Avritzer, 2009; Gohn, 2011). Na pesquisa em foco, a grande maioria das entidades tem participação em conselhos diversos de meio ambiente, de turismo, de educação, de assistência social, de agricultura, da criança e do adolescente, mais frequentemente de âmbito municipal, embora algumas entidades também participem em conselhos gestores estaduais. A participação em fóruns organizados pelos governos, sobretudo municipais, é comum na vida das ONGs locais e uma de suas funções precípuas. Assim, foram relatadas ora relações de diálogo e cooperação, ora de participação em conselhos gestores do Projeto de Gestão Integrada da Orla Marítima, conhecido como Projeto Orla $^{6}$, do Conselho Municipal de Meio AmbienteCOMAM - em João Pessoa, Conde e Cabedelo, do Conselho de Proteção Ambiental - COPAM - por parte da APAN, e em outros conselhos referentes a áreas conexas ao meio ambiente, como o turismo, as bacias hidrográficas, a agricultura, os respectivos municípios de origem e o conselho gestor da APA de Tambaba, município do Conde, coordenado pela Superintendência de Administração do Meio Ambiente - SUDEMA/PB. A participação em outros conselhos temáticos, que não de meio ambiente, foi mencionada por outras das ONGs estudadas, como é o caso da EVOT, que já teve participação nos Conselhos da Criança e do Adolescente e da Assistência Social.

O conjunto dos depoimentos teceu uma rede significativa de considerações sobre a qualidade da participação exercida nos conselhos gestores. Em primeiro lugar, ficou clara a predominância de um tipo de participação consultiva e não deliberativa. Algumas entidades relataram que a composição dos conselhos, muitas vezes, é assimétrica e coloca a voz das ONGs numa posição minoritária em relação à representação do governo, das empresas e demais entidades da sociedade civil, como o Conselho Regional de Engenharia e Agronomia - CREA-PB ${ }^{7}$, nem sempre afinados com a agenda e os propósitos das ONGs socioambientais. Essa assimetria é apontada como um obstáculo à possibilidade de formar maioria e de influenciar o rumo dos debates e das políticas públicas municipais e estaduais. No caso do $\mathrm{COPAM}^{8}$, a participação é deliberativa, mas, como a composição não é paritária, a representação ambiental da sociedade civil tende sempre a ficar em posição política desfavorável.

A representante da EVOT ressaltou, como dificuldade adicional à participação nos conselhos,

\footnotetext{
${ }^{6}$ O Projeto Orla é uma iniciativa do Ministério do Meio Ambiente - MMA, em parceria com diversos órgãos federais, estaduais, municipais, do setor privado e da sociedade civil que, desde 2004 até hoje, busca contribuir, em escala nacional, para disciplinamento de uso e ocupação da Orla Marítima.

${ }^{7}$ Até 2011 a entidade abrigava também os arquitetos, que neste ano criaram seu próprio conselho profissional.

${ }^{8}$ O COPAM é o Conselho de Proteção Ambiental do Estado da Paraíba, presidido pelo Secretário Extraordinário do Meio Ambiente, Recursos Hídricos e Minerais.
} 
o fato de que essa prática resulta numa grande demanda de trabalho, sobretudo em entidades com número reduzido de membros e sem qualquer tipo de remuneração. Segundo a depoente, esse fato torna a participação pesada e desinteressante para os conselheiros e suas entidades (Depoimento 3).

O depoimento da ACICA destaca aspectos importantes da participação nos conselhos gestores, tais como: a inconsciência de alguns conselheiros de que estão ali exercendo uma representação da coletividade; a pressão e a cooptação dos conselheiros pelas instâncias governamentais; a concepção ainda persistente de que os conselhos são mais concessões do Estado do que direitos da sociedade; e a flexibilização de normas e prazos que constitucionalmente regem a formação dos conselhos em defesa dos interesses governamentais. Ou seja, as conclusões das entidades convergem com outras pesquisas e reflexões sobre os novos instrumentos de participação instituídos pela Constituição de 1988 e que diagnosticam um dilema na participação praticada. Há, por um lado, um consenso sobre a necessidade de aprofundar as conquistas participativas na realidade brasileira. Por outro lado, reconhece-se que as novas experiências participativas ainda comportam distorções herdadas de uma cultura política marcada pelo clientelismo, pelo patrimonialismo e pelo financiamento privado de campanhas que se reflete adversamente no cotidiano da gestão pública (Monosowski, 1989; Acselrad, 2001; Camargo et al., 2004).

No tocante à relação das ONGs com as demais esferas sociais, merecem registro os elogios quase unânimes que as entidades pesquisadas dirigiram à ação dos Ministérios Públicos Estadual e Federal, por sua correção e postura republicana, figurando como aliados preferenciais dessas entidades em sua missão de denunciar as irregularidades verificadas e de defender direitos de cidadania. Alguns depoimentos também fizeram um reconhecimento pontual ao desempenho favorável da Fundação Cultural de João Pessoa - FUNJOPE - e do Serviço Brasileiro de Apoio às Micro e Pequenas Empresas - SEBRAE - no atendimento às demandas das ONGs locais.

\subsection{Estratégias de organização e financiamento}

Contrariamente às grandes ONGs nacionais e internacionais, que mobilizam grandes volumes de recursos financeiros, contam com elevado número de associados, detêm alto nível de profissionalização e gerenciam grandes projetos sociais, as ONGs locais estudadas têm estratégias muito mais simples e, muitas vezes, precárias de organização, financiamento e sobrevivência (Scherer-Warren, 1995; 1996; Herculano, 2000, Gohn, 2004; 2013).

Todas as entidades consultadas se organizam por meio do trabalho voluntário de seus associados, sem qualquer vínculo de emprego e trabalho profissional. Muitas delas reconhecem que esse é um fator limitante para uma ação continuada, abrangente e que vise objetivos de crescimento.

A adesão dos associados tende a ocorrer por afinidade com a temática ambiental, pela abordagem específica da ONG ou pelo descaso de ação governamental em relação ao problema ou conflito identificado na realidade regional.

As entidades estudadas reúnem um universo de associados que varia de 30 membros a 150 , ainda que destaquem, unanimemente, o fato de que os associados atuantes são uma minoria - algo em torno de $10 \%$ dos associados - em relação aos que têm uma participação passiva na entidade.

Em geral, definem em estatutos seus objetivos, atividades principais e seu campo de atuação, embo- 
ra esses objetivos sejam continuamente renovados pelas novas demandas e projetos que resultam do seu diálogo com os diversos setores da sociedade. Sua ação cotidiana envolve o atendimento a denúncias ambientais da comunidade, o desenvolvimento de projetos junto ao seu público-alvo, a participação em audiências e campanhas públicas, a organização de cursos de capacitação, palestras e protestos relacionados ao foco de sua ação, entre outras possibilidades.

A questão do financiamento marca o caráter quase amadorístico das ONGs estudadas, como possivelmente caracteriza o principal obstáculo à sua sobrevivência associativa. Sua principal fonte de recursos é a contribuição de sócios e simpatizantes, com exceção de uma ou outra entidade que ainda consegue aprovar projetos em editais universais de governos, fundações públicas e privadas, como é o caso da EVOT, da Acácia Pingo D’Ouro, da AMATA e da SONATA. Nenhuma das outras ONGs mencionou a participação em projetos por meio de editais. Embora a pesquisa não tenha tratado com detalhes a questão orçamentária das ONGs estudadas, um dos depoimentos forneceu uma pista sobre o assunto, ao relatar a participação em um evento sobre Terceiro Setor que tematizou a sustentabilidade das organizações:

Participamos de um encontro com ONGs sobre o Terceiro Setor para discutir esses problemas (de sustentabilidade financeira). Lá eles classificam as entidades por volume de captação anual: ONGs que concorrem a projetos de 50 a 100 mil reais são $10 \%$ no Brasil, de 500 mil a 5 milhões são 3\%, os que trabalham de 30 mil pra baixo é o resto que é onde nós nos encaixamos. E é esse universo de micro-ONGs que sustenta o trabalho social porque as grandes existem em beneficio de meia dúzia de pessoas, ou seja, se repete mais ou menos a estrutura e concentração da estratificação social brasileira (Depoimento 3).
Pesquisa da ABONG (2010) sobre a sustentabilidade das ONGs no Brasil apresenta um dado ainda mais contrastante, ao analisar as faixas orçamentárias das entidades associadas à ABONG. Entre elas encontraram desde organizações que têm recursos da ordem de $\mathrm{R} \$ 15$ milhões anuais até organizações que têm recursos da ordem de menos de R\$ 10 mil anuais.

Nenhuma das entrevistadas declarou ter parcerias e receber financiamentos de ONGs internacionais ou agências de cooperação internacional, mesmo porque entendem que o Brasil saiu do campo de prioridade dessas organizações, que passaram a priorizar a África e o Leste europeu, diante da nova condição semiperiférica do país e de mudanças políticas nos governos europeus, fonte de patrocínios expressivos. Já comentou-se acima o escasso acesso que o grupo de entidades pesquisado tem em relação às fontes públicas de financiamento, seja pela baixa disponibilidade de oferta dos governos locais, seja pela competitividade e difícil acesso aos editais nacionais. Nesse sentido, alegam os obstáculos burocráticos do processo de captação e a precária estrutura profissional de que dispõem. Com relação às fontes privadas/empresariais, novamente, apontam dificuldades com a acirrada competição entre as organizações e a ausência de capacidade técnica para alcançar alguma possibilidade de sucesso na captação. Diegues (2008) agrega à análise sobre captação de recursos por parte de ONGs ambientalistas a questão da seletividade político-ideológica dos projetos por parte das grandes ONGs internacionais e dos patrocinadores empresariais. Segundo o autor, no campo ambientalista, seriam privilegiados os projetos que se dedicam a temas ecológicos em sentido estrito, como a defesa de uma espécie ou de um ecossistema ameaçado, e preteridos os projetos que envolvem conflitos socioambientais, como aqueles que tratam de populações tradicionais, a 
saber, indígenas, atingidos por barragem, quilombolas, seringueiros, pescadores artesanais e grupos extrativistas, entre outras categorias.

\subsection{Percepção dos problemas ambientais locais}

Esse núcleo temático procurou compreender como as diferentes entidades diagnosticam o cenário socioambiental da grande João Pessoa por meio de uma caracterização do que julgam ser os principais problemas da cidade a merecer cuidados e políticas públicas.

A listagem de problemas inclui impactos na região metropolitana de João Pessoa, com referências: à expansão imobiliária, ocupação irregular e desordenada de áreas de preservação e áreas impróprias a moradias; ao desmatamento e à arborização urbana insuficiente; à poluição dos rios e dos trechos de praia onde os rios poluídos desaguam; à falta de saneamento, em especial quanto a tratamento de esgotos; ao crescimento de problemas de mobilidade urbana; à expansão turística desordenada; à coleta seletiva de resíduos sólidos insuficiente; a indústrias poluentes, como as de cimento e de porcelanato, carcinicultura; à falta de espaços comunitários além da praia e dos shoppings; e ao lixo marítimo na praia de Tambaba no município do Conde, grande João Pessoa.

Todos os entrevistados concordam que esses impactos são agravados pela falta de planejamento e de ordenamento urbano e pelo baixo nível educacional e de consciência pública da própria população sobre os problemas ambientais. Ou seja, referem-se à precária regulação governamental, que não faz cumprir as leis existentes, não planeja, não controla, não fiscaliza os agentes poluidores, opera intervenções que implicam em degradação do meio e aprova licenciamentos de obras e instalações, no mínimo, questionáveis. Considerou-se também que os governos locais são, muitas vezes, omissos ante iniciativas irregulares praticadas pelo setor privado. Indagado como percebia a origem dos problemas ambientais, um dos depoentes resumiu da seguinte forma: "Percebo os problemas ambientais como o resultado da ação do poder privado sobre o espaço público e pelo descaso do poder público em conter essa destruição" (Depoimento 3).

Os problemas elencados não são diferentes daqueles verificados nas grandes cidades brasileiras. Revelam apenas uma menor intensidade relativa em relação às maiores metrópoles, dada a escala regional e comparativamente ao menor peso que têm os impactos decorrentes da atividade industrial na grande João Pessoa.

\subsection{Principais dificuldades à sobrevivência e ao desempenho de suas funções}

É sabido que, com exceção do clube das grandes ONGs ambientais nacionais e internacionais, que contam com fontes vultosas de financiamento público e, sobretudo, privado, como é o caso do Greenpeace, WWF - World Wildlife Fund, The Nature Conservancy - TNC, a Conservação Internacional - CI - e a SOS Mata Atlântica, entre outras, as menores ONGs contam com inúmeras dificuldades de sobrevivência por razões diversas (Diegues, 2008).

No caso estudado, as razões principais, por ordem decrescente de importância, são: limitados recursos financeiros; incapacidade de garantir um quadro de profissionais capacitados e em tempo integral; escassa infraestrutura física de instalação, transporte, comunicação e divulgação; dificuldade de atrair e manter novos voluntários, dada a alta 
rotatividade dessa forma de vinculação e mobilização. Esse conjunto de obstáculos é inegavelmente comum a todas as entidades pesquisadas, mas pode ser desdobrado em outros limites menos visíveis, mas nem por isso menos importantes.

No depoimento da AMATA, que atua no município do Conde, onde as praias e as residências de veraneio são numerosas, aparece o fato de que essa população flutuante e a sazonalidade que a caracteriza resultam em menor envolvimento dessa população com os problemas locais e, por extensão, com a entidade ambiental regional (Depoimento 7).

O depoimento da ACICA chamou atenção para os problemas relativos à precária cultura política municipal, caracterizados pelo crescente descrédito nas instituições políticas, pelo limitado nível de cidadania e reconhecimento de direitos socioambientais e por uma compreensão convencional da política, restrita ao campo parlamentar, eleitoral e dos partidos políticos, mas não aberta à participação da sociedade e ao público em geral (Depoimento 4). Um dos aspectos que a produção teórica sobre o associativismo de ONGs e novos movimentos sociais identifica como inovador no cenário político pós anos 1990 é justamente a ressignificação do conceito de política, que tende a politizar questões antes tidas como pertencentes à esfera privada e a deslocar o campo do fenômeno político para fora da sociedade política convencional, compreendida pelos governos, parlamentos, partidos e sindicatos, para incluir todos os demais âmbitos da vida e da ação social (Habermas, 1981a; 1981b; Avritzer, 1993; Costa, 1994; Gohn, 1997; Vieira, 2011).

Além dos obstáculos mencionados, a EVOT, entidade que mais depende da aprovação de projetos em editais, expôs como obstáculos nesse processo: o excesso de burocracia que os projetos demandam, a concentração regional de recursos disponíveis para esses fins em torno das regiões sul e sudeste, a ocorrência de fundos de recursos de órgãos e empresas estatais e paraestatais partidariamente comprometidos e as campanhas recentes de descredibilização das ONGs, a partir de denúncias e ocorrências de irregularidades praticadas por algumas organizações (Depoimento 3).

\subsection{Cultura ambiental local}

A cultura ambiental supõe o conjunto coerente de discursos, valores, saberes, atitudes e práticas cotidianas resultantes da valorização do meio ambiente e do reconhecimento de que é preciso defendê-lo dos processos contemporâneos que promovem sua degradação. Ela nasce e se desenvolve como resposta social à crise e aos problemas ambientais, como necessidade de compreender seus significados complexos e de encontrar caminhos para sua superação. É uma categoria que dá a medida da internalização pela população local da preocupação, do cuidado e de atitudes práticas de conservação ambiental (Kaufman, 2009; Andrade \& Lima, 2012).

Nos depoimentos reunidos, ainda que heterogêneos, sobressai a percepção geral de que a cultura ambiental é um dado presente e pervasivo na vida da população pessoense, mas ainda de modo incipiente. Partindo dessa constatação geral, os diversos depoentes procuraram qualificar sua impressão sobre o tema agregando observações significativas.

$\mathrm{O}$ depoimento 2 destacou a fragilidade do associativismo e dos valores coletivistas na população da grande João Pessoa e o predomínio do individualismo como um fator a retardar o avanço da cultura ambiental local (Depoimento 2).

Outros depoimentos justificaram a incipiência da cultura ambiental local a partir de outros argumentos. 
Segundo o depoimento 6, é necessário ter informação sobre os problemas, mas isso não basta, é preciso se organizar e reagir aos impactos da degradação (Depoimento 6).

O depoimento 3, corroborando que a cultura ambiental é limitada entre a população da região metropolitana, entende que isso decorre do nível de educação da população e da qualidade das escolas que, segundo o depoente, têm evoluído lentamente. Acrescenta que educação ambiental é mais do que comemorar o dia da árvore, supõe a internalização da questão ambiental na vida cotidiana (Depoimento 3).

Segundo o depoimento 5, as pessoas seguem jogando lixo nas ruas, não reivindicam seus direitos a uma cidade melhor, com mais parques e praças e ainda não aprenderam a valorizar os bens e serviços ambientais existentes. A mesma narrativa considera que os equipamentos artificiais e tecnológicos, como os shopping centers, ainda são bem mais valorizados pela população do que os bens ambientais (Depoimento 5).

O depoimento 4 concorda que a cultura ambiental local ainda é precária e está associada ao baixo nível de cidadania da população. Entende que há pensadores, movimentos e intelectuais preocupados com o meio ambiente, mas que a população em geral, embora sofra os efeitos da degradação, não prioriza o tema. Argumenta que a temática ambiental tende a ser tratada de forma ingênua e estritamente ecológica, em detrimento das dimensões políticas e econômicas que a constituem (Depoimento 4).

Para o depoimento 1, a resposta ambiental da população é variável e se corporifica em alguns casos, embora em outros predomine a indiferença. Ilustra a percepção mostrando que a população tem reagido historicamente em defesa da orla e contra os espigões e às ameaças da especulação imobiliária como reage contra os maus tratos aos animais, mas em outros temas o engajamento e o compromisso declinam e caem na indiferença (Depoimento 1).

O conjunto dos depoimentos converge, portanto, para a percepção de que a cultura ambiental já despertou no seio da população, mas ainda tem um caminho a percorrer para se qualificar e fortalecer no interior da cultura regional.

\section{Contribuição das ONGs à legitimação social dos problemas ambientais}

As contribuições que as ONGs têm prestado às comunidades e sociedades onde se inserem, em termos de legitimação social dos problemas ambientais, revelaram uma multiplicidade de funções objetivas e simbólicas que têm condicionado tanto a cultura material quanto imaterial da região pesquisada.

As narrativas reunidas mostram como, nas últimas décadas do século XX, os problemas ambientais ganharam, crescentemente, visibilidade e significados que não possuíam e que as ONGs regionais tiveram um protagonismo decisivo neste processo. Sem dúvida que a formação de uma questão ambiental na região foi também condicionada por outros atores sociais e influências dos contextos nacionais e internacionais, mas estes fatores externos não poderiam ter se enraizado localmente sem a contribuição dos movimentos e entidades da sociedade civil. Nesse sentido, legitimação e institucionalização foram processos que se alimentaram mutuamente e, em ambos os casos, a presença e a ação das ONGs foi de fundamental importância na construção de sentidos, valores, discursos e práticas que instituíram uma cultura ambiental na região.

A contribuição educacional aparece com bastante nitidez e se associa ao potencial informativo, 
de formação de consciência e de geração de um conhecimento práxico sobre os problemas locais. Alguns depoimentos ressaltaram o fato de que esse potencial educativo não beneficiou e educou apenas a opinião pública, mas incluiu os próprios militantes e voluntários das entidades, o poder público, as empresas e as mídias com as quais se relacionaram ao longo do tempo.

Destacou-se, nesse sentido, que o papel educativo das ONGs se manifestou duplamente, tanto no sentido de ambientalização da sociedade quanto no sentido de educação política. Isto porque exercitou e forneceu exemplos práticos de como defender direitos, de como politizar as questões ambientais e atuar no cenário político-institucional. Isso equivale a dizer que as entidades pesquisadas cumpriram um papel fundamental de fortalecimento da esfera pública, na medida em que denunciaram, debateram e deram visibilidade a problemas que sem essa ação permaneceriam na obscuridade. As narrativas reunidas mostraram ainda como as ONGs se envolveram na responsabilização dos agentes da degradação, na cobrança de fiscalização ambiental por parte dos órgãos governamentais e de aplicação das leis existentes. Esse papel se alinha com o diagnóstico habermasiano das sociedades contemporâneas, onde as entidades da sociedade civil, como os movimentos sociais e as ONGs, definidos pelo interesse público não estatal, estariam destinadas à defesa do mundo da vida contra os excessos e abusos cometidos pelo mercado e pelo Estado (Habermas, 1981a; 1981b).

Vimos anteriormente como as ONGs locais exercem representações diversas em fóruns participativos, como os conselhos e comitês de governança ambiental, e como essa representação se reflete na formulação de políticas públicas. É relevante entender que a atuação das ONGs regionais se converte, em última instância, em um conhecimento estratégico para diagnosticar a realidade ambiental municipal e para subsidiar políticas públicas de combate à degradação. Os depoimentos constataram que a ação continuada das ONGs socioambientais produziu, através dos tempos, conquistas objetivas para a cidade e sua população, como são exemplos o fim da caça às baleias, a luta que resultou na limitação do gabarito das construções na orla marítima, o combate à poluição dos rios pelos resíduos do sistema sucroalcooleiro e as lutas pela preservação das falésias do Cabo Branco, entre tantas outras.

Discutiu-se anteriormente a relativa limitação das ONGs em termos de resultados materiais e objetivos às comunidades onde atuam, devido aos escassos recursos financeiros, humanos e técnicos de que dispõem. É possível, contudo, dizer, que a parte mais significativa de sua atuação se expressa de forma simbólica e cultural quando intervêm em espaços de participação social e de educação política, no debate e na politização de novas temáticas que a ação estatal não alcança, na inovação de saberes e arranjos interativos e na defesa de direitos humanos e difusos.

\section{Considerações finais}

Considerando a importância política, social e cultural das ONGs socioambientais na grande João Pessoa, ainda são poucos os estudos a elas dedicados na pesquisa local e regional. É preciso reconhecer que dadas a população e a extensão da região metropolitana de João Pessoa, o número de entidades voltadas ao tema e o seu porte ainda são menos expressivos do que seria natural presumir. Contudo, também é necessário reconhecer que, apesar deste fato, as entidades existentes cumprem funções relevantes na vida pública regional, como se constatou na análise precedente. 
A pesquisa demonstrou que, ao desenvolverem sua ação, essas entidades atuam na defesa do interesse público, quando denunciam os problemas ambientais locais, quando promovem o debate e a deliberação sobre sua ocorrência na esfera pública, quando formam e transformam a consciência pública sobre tais problemas, quando defendem direitos coletivos associados à qualidade de vida, quando qualificam e ampliam a participação e a cidadania local, quando representam a coletividade nas instâncias participativas e quando empreendem ações que o poder público e a iniciativa privada não realizam por desinteresse ou incapacidade.

Tendo funções públicas tão relevantes, é forçoso reconhecer que as ONGs analisadas ainda não gozam do reconhecimento e do apoio devido por parte dos governos, da própria população e da iniciativa privada. Por essas e outras razões, essas entidades contam com inúmeras dificuldades de sobrevivência, que incluem: restrições financeiras, de infraestrutura e de recursos humanos capacitados que permitam a expansão de sua ação socioambiental.

A análise revelou os desafios que as ONGs encontram para participar na formulação e na implementação das políticas públicas municipais e estaduais, devido às imperfeições dos instrumentos de participação, à interferência empresarial na ges-

\section{Referências}

ABONG. Sustentabilidade das ONGs no Brasil: acesso a recursos privados. Rio de Janeiro: ABONG, 2010.

Acselrad, H. Cidadania e meio ambiente. In: Acselrad, H. (Org.). Meio ambiente e democracia. Rio de Janeiro: IBASE, 1992. p. 18-31.

Acselrad, H. Políticas ambientais e construção democrática. In: Viana, G.; Silva, M. (Orgs.). O desafio da sustentabilida- tão pública por meio do financiamento privado de campanhas político-eleitorais, ao escasso interesse de deputados e vereadores pelos temas ambientais da agenda local e à relativa indiferença de setores da população local frente aos mesmos problemas. Foi, por outro lado, possível constatar relações mais cooperativas com os Ministérios Públicos Federal e Estadual, com as universidades e centros de ensino, com os meios de comunicação e com determinados órgãos governamentais, a depender da sensibilidade ambiental dos gestores no comando da administração.

Diversas das ONGs entrevistadas revelaram esforços de cooperação entre entidades ambientais na região, embora tenham concluído que tais esforços ainda não foram suficientes para construir uma rede de ONGs e movimentos capaz de lutar conjuntamente na defesa do interesse ambiental público e na resolução de seus problemas comuns.

Em resumo, a pesquisa demonstrou que, a despeito dos problemas que vivenciam cotidianamente, as ONGs ambientais locais têm desenvolvido um papel fundamental na vida pública da grande João Pessoa no que diz respeito à defesa das causas ambientais, à ampliação da esfera pública regional e ao avanço progressivo da cultura política e da participação democrática. de: um debate socioambiental no Brasil. São Paulo: Editora Fundação Perseu Abramo, 2001. p. 75-96.

Andrade, M. O. de; Lima, G. F. da C. (Orgs.). Gestão e desenvolvimento socioambiental na Paraíba: concepções e práticas. João Pessoa: Editora da UFPB, 2012.

Avritzer, L. Além da dicotomia Estado/Mercado: Habermas, Cohen e Arato. Novos Estudos CEBRAP, 36, 213-222, 1993. 
Disponível em: <http://novosestudos.uol.com.br/v1/files/ uploads/contents/70/20080625_alem_da_dicotomia.pdf>.

Avritzer, L. Sociedade civil e participação no Brasil democrático. In: Avritzer L. (Org.). Experiências nacionais de participação social. São Paulo: Cortez, 2009. p. 27-54.

Camargo, A. et al. (Orgs). Meio ambiente Brasil: avanços e obstáculos pós-Rio-92. Rio de Janeiro: FGV, 2004.

Carvalho, I. C. de M. A invenção ecológica: narrativas e trajetórias da educação ambiental no Brasil. Porto Alegre: Ed. Universidade/UFRGS, 2001.

Cohen, J.; Arato, A. Civil society and political theory. Cambridge: MIT Press, 1992.

Costa, S. Esfera pública, redescoberta da sociedade civil e novos movimentos sociais no Brasil: uma abordagem tentativa. Novos Estudos CEBRAP, 38, 38-52, 1994. Disponível em: $<$ http://novosestudos.uol.com.br/v1/files/uploads/ contents/72/20080626_esfera_publica_redescoberta.pdf $>$.

Dagnino, E. Sociedade civil, participação e cidadania: de que estamos falando? In: Mato, D. (Coord.). Políticas de ciudadanía y sociedad civil en tiempos de globalización. Caracas: FACES, Universidad Central de Venezuela, 2004. p. 95-110.

Diegues, A. C. A globalização da proteção da natureza: o papel das grandes ONGs transnacionais e da ciência. In: Dupas, G. Meio ambiente e crescimento econômico: tensões estruturais. São Paulo: Ed. UNESP, 2008. p. 131-164.

Gohn, M. da G. Teoria dos movimentos sociais: paradigmas clássicos e contemporâneos. São Paulo: Edições Loyola, 1997.

Gohn, M. da G. Sociedade civil no Brasil: movimentos sociais e ONGs. Nómadas (Col.), Universidad Central Colombia, 20, 140-150, 2004. Disponível em: <http:// www.ucentral.edu.co/images/editorial/nomadas/docs/nomadas_20_12_sociedad.PDF $>$.

Gohn, M. da G. Movimentos sociais na contemporaneidade. Revista Brasileira de Educação, 16(47), 333-361, 2011. doi: 10.1590/S1413-24782011000200005

Gohn, M. da G. Sociedade civil no Brasil: movimentos sociais e ONGs. Meta: Avaliação, 5(14), 238-253, 2013. Disponível em: $<\mathrm{http}: / /$ revistas.cesgranrio.org.br/index. $\mathrm{php} / \mathrm{metaavaliacao} /$ article/viewFile/145/pdf $>$.
Gonçalves, H. S.; Menescal, A. K. Organizações não governamentais: solução ou problema? São Paulo: Estação Liberdade, 1996.

Habermas, J. The theory of communicative action. Boston: Beacon Press, 1981a.

Habermas, J. New Social Movements. Telos, St. Louis, 49, 33-37, 1981b. Disponível em: <dx.doi. org/10.3817/0981049033>.

Hannigan, J. Sociologia ambiental. Petrópolis, RJ: Vozes, 2006.

Herculano, S. ONGs e movimentos sociais: a questão de novos sujeitos políticos para a sustentabilidade. In: Herculano, S. (Org.). Meio ambiente: questões conceituais. Niterói: UFF/PGCA - Riocor, 2000. p. 123-155.

Kaufman, C. Estudos culturais, mídia e meio ambiente: Tecendo saberes para uma cultura ambiental. In: Anais do Quinto Encontro de Estudos Multidisciplinares em Cultura, UFBA, 2009.

Landim, L. Experiência militante: histórias das assim chamadas ONGs. Lusotopie, 1, 215-239, 2002. Disponível em: $<\mathrm{http}$ ://www.lusotopie.sciencespobordeaux.fr/landim.pdf $>$.

Leis, H. R. A modernidade insustentável: as críticas do ambientalismo à sociedade contemporânea. Petrópolis: Vozes; Florianópolis: UFSC, 1999.

Lima, G. F. da C. Educação Ambiental no Brasil: formação, identidades e desafios. Campinas, SP: Papirus, 2011.

Lipietz, A. A ecologia política: solução para a crise da instância política? In: Alimonda, H. (Ed.). Ecologia política. Buenos Aires: CLACSO, 2002. p. 15-26.

Maia, R. C. M. O papel democrático da sociedade civil em questão. Lua Nova, 81, 147-174, 2010. Disponível em: $<$ http://www.scielo.br/pdf/ln/n81/a07n81.pdf $>$.

Martell, L. Ecology and society. Oxford: Blackwell Publishers, 1994.

Martinez-Alier, J. O ecologismo dos pobres: conflitos ambientais e linguagens de valoração. São Paulo: Contexto, 2007.

Monosowski, E. Políticas ambientais e desenvolvimento no Brasil. Cadernos FUNDAP, 9(16), 15-24, 1989. 
Montaño, C. Estado, classe e movimento social. São Paulo: Cortez, 2010.

Offe, C. New social movements: challenging the boundaries of institutional politics. Social Research, 52(4), 817-868, 1985.

Pádua, J. A. O nascimento da política verde no Brasil: fatores exógenos e endógenos. In: Leis, H. R. (Org.). Ecologia e política mundial. Rio de Janeiro: Fase/Vozes, 1991. p. 135-161.

Pelizzoli, M. L. As correntes da ética ambiental. Petrópolis, RJ: Vozes, 2002.

Pinto, C. R. J. As ONGs e a política no Brasil: presença de novos atores. Dados, 49(3), 651-670, 2006. doi: 10.1590/ S0011-52582006000300008

Roszac, T. A contracultura. Petrópolis, RJ: Vozes, 1972.

Scherer-Warren, I. ONGs na América Latina: trajetória e perfil. In: Viola, E.; Leis, H. (Orgs.). Meio ambiente, desenvolvimento e cidadania. São Paulo: Cortez, 1995. p. 161-180.

Scherer-Warren, I. ONGs: Os novos atores da "aldeia global". In: Anais da XX Reunião Anual da ANPOCS, Caxambu, MG, out./1996. Disponível em: $<$ http://portal.anpocs. org/portal/index.php?option $=$ com_docman\&task $=$ doc view\&gid=5332\&Itemid $=361>$.

Scherer-Warren, I. Redes de movimentos sociais na América Latina: caminhos para uma política emancipatória? Cader- no CRH, Salvador, 21(54), 505-517, 2008. doi: 10.1590/ S0103-49792008000300007

Sobottka, E. A. Organizações civis buscando uma definição para além de ONGs e terceiro setor. Civitas, 2(1), 81-95, 2002. Disponível em: <http://revistaseletronicas.pucrs.br/ ojs/index.php/civitas/article/view/89>.

Sorj, B. Sociedades civis e relações Norte-Sul: ONGs e dependência. Rio de Janeiro: Centro Edelstein de Pesquisas Sociais, 2005.

Tavolaro, S. B. de F. Movimento ambientalista e modernidade: sociabilidade, risco e moral. São Paulo: Annablume/ Fapesp, 2001.

Teixeira, A. C. C. Identidades em construção: as organizações não governamentais no processo brasileiro de democratização. São Paulo: Annablume/Fapesp/Instituto Pólis, 2003.

Toledo, G. A. da C. O homem e a baleia: aspectos históricos, biológicos, sociais e econômicos da caça na Paraíba. João Pessoa: Dissertação (Mestrado) - UFPB/PRODEMA, 2009.

Vieira, L. Cidadania e globalização. Rio de Janeiro: Record, 2011.

Viola, E. J. O movimento ecológico no Brasil (1974-1986): Do ambientalismo à ecopolítica. In: Pádua, J. A. (Org.). Ecologia e política no Brasil. Rio de Janeiro: Espaço e Tempo/IUPERJ, 1987. p. 63-109. 